\title{
HISTORICAL AND LITERARY TEXTS AS THE BASIS FOR TEACHING A NON-NATIVE LANGUAGE
}

\section{Sayyora Amideevna Alimsaidova}

Candidate Of Pedagogical Sciences, Associate Professor, Department Of "Russian Language And Literature", Kokand State Pedagogical Institute Named After Mukimi

\section{ABSTRACT}

This article reveals the criteria for the selection of historical and literary texts for educational purposes. The correct selection of historical and literary texts will make it possible to correctly assess the textual basis of existing textbooks for secondary schools, and will also serve not only as a means of improving students' Russian speech, but will also play a significant role in the formation of sociolinguistic competence.

\section{KEYWORDS:- Historical and literary text, principle, morality, motivation, sociolinguistic competence.}

\section{INTRODUCTION}

The leading priority of the National Model of Personnel Training is a personality that is formed in a fundamentally new economic and political environment. Ensuring the implementation of this priority is based on a comprehensive consideration of world experience, living conditions of our people, their traditions, customs and habits, way of life.

It is the national orientation of education that lies in its organic unity with national history, folk traditions and customs, preservation and enrichment of the culture of the peoples of Uzbekistan, recognition of education as the most important instrument of national development, respect for the history and culture of other peoples [2,1997].

The selection of historical and literary texts of national importance and considered not only as a unit of study, but also as the main way of organizing educational material in the lesson contributes to the deepening of the motivation for learning the Russian language. The reliance on the use of the motivational capabilities of historical and literary texts ensures the development of mainly communicatively valuable and personally significant types of work on the texts, which have a positive effect on improving the skills of independent work, and most importantly, on the upbringing and deepening of the feeling of love for the Motherland, the native land.

The communication-oriented system of teaching a non-native language is characterized by the convergence of the teaching activity with the activity of real communication. And it is expressed, first of all, in the selection of educational material (coherent texts) and its special organization, in which the formation of the speech activity of students is ensured. 
This is facilitated by the fact that texts about outstanding people of the country of the target language (Russia) are studied in parallel with the selected local history texts of a historical and literary nature (history and culture of Uzbekistan), which creates conditions for the dialogue of languages and cultures, which today is acquiring a huge socio-political and spiritual and moral significance.

We agree with the point of view of N.P. Shulgina that to teach trainees "to use the Russian language as a means of communication, a means of knowing the world and oneself in it, familiarizing with culture, developing in them the ability to competently, actively and creatively master all types of speech activity provide an opportunity for lessons, where the text acts as the highest unit of learning, in which all elements of the language system are integrated, combined and synthesized" [3, 2003].

\section{THE MAIN FINDINGS AND RESULTS}

Since the educational text for students of secondary schools is at the same time a source of information, a model and a means of teaching the construction of an independent monologue statement, it is necessary to pay serious attention to the sample as the primary source, with the help of which students develop key skills and abilities of coherent speech.

In order to establish criteria for the selection of the text component of teaching the Russian language in general education schools, we studied recommendations for the selection of texts for non-Russian students, developed at the end of the XX - beginning of the XXI century by famous scientists-methodologists (N.M. Shansky, N.Z.Bakeeva, S. K. Folomkina, T. S. Kudryavtseva, E. A. Bystrova, V. I. Kapinos, B. M. Esadzhanyan), as well as dissertation research on the methodology of teaching the Russian language in the Uzbek school (A. I. Andriyanova, L. T.
Akhmedova, O. V. Kon, E. A. Lagai, M. M. Davlyatova and others).

The analysis of the above sources made it possible to group, isolate and refract to the problem we are investigating the following main criteria for the selection of historical and literary texts of a historical and literary nature for linguodidactic purposes.

The first criterion is that the text should be informatively valuable (new and relevant), contribute to expanding the horizons of students.

The second criterion is that the texts should contain a local history component, in particular, reveal the peculiarities of everyday life, culture, traditions, peculiarities of the character of the Uzbek people, aesthetic tastes, natural conditions, and most importantly, the pivotal milestones of history. At all times, knowledge of the history of one's native country was considered a necessary condition for the formation of a comprehensively developed personality, a patriot of one's Motherland. This constitutes the richest educational and developmental and valuable culturological material.

The third criterion is that the degree of information content of the texts must correspond to the intellectual and cultural level of the student's development, that is, the basic information must be understandable.

The fourth criterion is that the texts should be justified in terms of the communicative needs and interests of students, focus on discussion, reasoning and thereby contribute to the implementation of verbal communication in the lesson; be entertaining and emotional.

The fifth criterion is that the texts should be accessible for perception and understanding from the point of view of the psychological and age characteristics of students. 
The sixth criterion is that the texts should reflect the real spheres of communication, contribute to the natural enrichment of students' speech with the vocabulary and constructions of the modern Russian language.

Any type of speech has its own linguistic characteristics. For example: in narrative texts, the main actions are successively replacing each other. For example:

"Acquaintance with any city is always interesting, like a journey into the region of the unknown and the beautiful. Getting to know a city known in history is doubly tempting. This is one of the ancient cities of Uzbekistan and all of Central Asia - Kokand. It is unique with its "face", role and significance in history, cultural heritage, extraordinary fate, fame and fame, which, of course, are conditioned by the work, talent and deeds of its inhabitants.

It went down in history at the beginning of the 17th century as the capital of the Kokand Khanate, a major trade and cultural center of Central Asia. It is no coincidence that today in Uzbekistan Kokand is called the city of poets. In the anthology of Uzbek poetry, researchers count more than 100 names of remarkable masters of the word - Kokand people. Among them are the most famous poets Mukimi, Furkat, Gulkhani, Zavki, Nadira, Anbar Atin, Uvaysi and many others" (N. Lukashov).

The connection between sentences should be chain, realized with the help of conjunctions, pronouns, adverbs, synonymous substitutions, lexical repetitions.

For description texts, the enumeration of signs of objects, phenomena, persons are inherent, the presence of predicates - verbs with the same type of meaning of simultaneity of action. For example:

"Kokand is located in the western part of the Fergana Valley, in the lower reaches of the Sokh
River, 25 kilometers from the Syrdarya River. The green attire of the city is rich and varied. In the courtyards and on the streets, in the spring, they delight the eye with their exuberant flowering of apple and pear, cherry and sweet cherry, apricot and peach, dense leafy foliage saves the vineyard from the heat, exotic trees of pomegranate and figs bring pleasure both with flowering and fruits. On the streets, in parks and squares, powerful plane trees give cool and clean air to residents, the patriarchs of forests - oaks, curly maples, pyramidal and silvery poplars, powerful centenarians - elm, unpretentious talas and weeping willows, chestnuts, ash trees, acacia and many other decorative trees" (N. Lukashov).

Texts of this kind are characterized by parallel communication carried out using structural parallelism of syntactic constructions.

For texts, reasoning is characterized by a causeand-effect relationship between judgments. Therefore, three parts are required in them: thesis - the main statement, a clearly formulated thought; proof, arguments supporting the thesis put forward; conclusion following from the evidence (conclusion, generalization). They are dominated by linguistic means expressing causeand-effect relationships (circumstance of cause, conditions, complex sentences with subordinate reasons, conditions; evaluative words, assertion or denial of something). For example:

"Do we really have to love our land only because it is rich, that it gives abundant harvests, that its natural forces can be used for our well-being?

We love our native places not only for this. We also love them because they are beautiful for us.

I love my native land because it is beautiful, although all its charm is revealed not immediately, but very slowly, gradually" (According to K.G. Paustovsky).

\section{Results AND Discussion}


The functioning of speech types is inextricably linked with speech styles. Scientists methodologists (N.M. Shansky, K.Z.Zakiryanov, Z.P. Daunene and others) argue that in the textbooks of the Russian language for the development of oral speech, texts of both journalistic and popular science style, and literary texts.

According to our observations, stories, essays, excerpts from the works of famous poets and writers of Uzbekistan can be effectively used in the classroom and in full, and in fragments, and in a compressed form. The degree and form of adaptation of texts depend on the stage of training, on the level of general development of students, on their language readiness. Our experience convinces us that a text is suitable if it is adaptive, that is, with minor changes, it is applicable for teaching and educational purposes.

Based on our many years of experience, it became clear that the role of the artistic and journalistic text in the development and improvement of the Russian speech of students of general education schools, in particular, in the formation of sociolinguistic competence using historical and literary texts of a historical and literary nature, is enormous. This is understandable: after all, literature is the great treasury of language. It is in her that language finds its fullest and most perfect expression. In addition, literature is a textbook of life, a source of deep moral and aesthetic values.

In the process of selecting historical and literary texts of a historical and literary nature, we proceeded from the fact that the intensity of the productive speech of students, based on literary material (literary text), directly depends on the degree of understanding of the text, on the multilevel nature of the text. The first level of understanding (the level of knowledge) is mainly associated with the degree of completeness, and the second level (the level of meaning) - with the degree of depth of understanding. At the first level, the perception and assimilation of the figurative nature of the word, the activation of emotional and evaluative vocabulary is extremely important. On the second, the ability to highlight and define the main idea of the text, the main aspects of the content, individual facts, the ability to anticipate information, summarize it, comprehend and evaluate (from the point of view of cognitive, educational and aesthetic value) is formed.

We agree with the position expressed by researchers L.P. Ataeva, T.N. Martinovich and L.L. Novikova that "the creation of a motivational basis for educational actions leading to the mastery of speech skills and abilities is achieved by the selection of educational material that is meaningful for students. "[1, 1989]. Such material is a local history text of a historical and literary nature, providing for the correspondence of the methods of modeling primary texts that students hear and read, and secondary texts that students create themselves. It follows from this that in the lessons of the Russian language, it is necessary to create such conditions for students of lyceums in which they will take part adequately to a specific life situation.

\section{Conclusion}

The above criteria for selecting texts, on the basis of which the selection of historical and literary texts will be carried out, will allow us to objectively evaluate the textual basis of existing textbooks for secondary schools, as well as select new, interesting, personally significant additional texts about the history and culture of Uzbekistan, which will serve not only as a means of improving students' Russian speech, but will also play a significant role in solving educational and cognitive tasks in the educational process.

In conclusion, we note that reliance on historical 
CURRENT RESEARCH JOURNAL OF PEDAGOGICS 2(10): 204-208

October 2021 DOI: https://doi.org/10.37547/pedagogics-crjp-02-10-37

ISSN 2767-3278

(C)2021 Master Journals

Crossref do) 81 Google

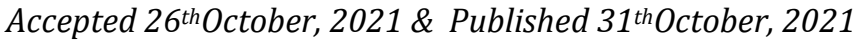

and literary texts will contribute to the formation of the sociolinguistic competence of students in general education schools, activate their creative abilities, and have a positive effect on the comprehensive development of the student's personality.

\section{REFERENCES}

1. Ataeva L.P., Martinovich T.N., Novikova L.L. (1989) Methods of creating and maintaining motivational readiness of students' interests for speech activity in teaching the language of the specialty. Problems of preparing foreign studentsnon-philologists and specialists for professional communication in Russian: Abstracts. report and mess. int. conf. Tashkent. - pp. 31 - 32.

2. Andriyanova V.I. (1997) Theory and practice of teaching Uzbek schoolchildren to oral communication in Russian. Author's abstract. Doctor of Pedagogical Sciences. - Tashkent. - p. 39.

3. Shulgina N.P. (2003) Working with text as a means of forming a student's personality. Russian language at school. No. 3. - pp. 310.

4. Lukashov N. (1988) Kokand. Reference guide. - Tashkent: Uzbekistan. - p. 77.

5. Paustovsky K. (1986) Smoke of the Fatherland: Stories. - Moscow: Pravda. - p. 456. 